How COVID-19 has accelerated the shift towards a more sustainable fashion industry

A Thesis
Presented to
The Faculty and the Honors Program
Of the University of San Diego

By

Samantha Casey

Business Administration

2021 


\begin{abstract}
Sustainability in fast fashion is a pertinent issue as the fashion industry is one of the most environmentally damaging industries. Fashion retailers have started to integrate sustainability initiatives, but consumer preference is vital to making firms change their practices. As the COVID-19 pandemic hit the world in 2020, worldwide lockdowns exposed the fragility of the consumer-driven fast-fashion business model. This thesis will examine how COVID-19 has and will continue to impact sustainability in the fashion industry. More specifically, this thesis will examine the implications of consumer sustainability preferences brought about by the pandemic. These implications accelerate the preexisting sustainability trends in the fashion industry by pushing companies to appeal to the consumer preferences brought about by COVID-19. This project provides insights for business managers in the fashion industry to thrive post-pandemic.
\end{abstract}




\section{How COVID-19 has accelerated the shift towards a more sustainable fashion industry}

Fashion is a $\$ 2.4$ trillion-dollar industry that employs approximately 60 million people globally, but $\$ 500$ billion of that value is lost annually due to a lack of sustainability, such as clothing underutilization and inadequate recycling (United Nations Alliance for Sustainable Fashion, 2020). Fast fashion, a significant subset of the broader fashion industry, reported a global market value of 36 billion U.S. dollars in 2019 (Sabanoglu, 2020). The value of this industry is predicated on intricate global relationships of producers and consumers. This study will focus on the impact of the worldwide 2020 to 2021 COVID-19 pandemic on the sustainability of the fast fashion industry in North America and Europe. The main question looking to be addressed is whether COVID-19 will accelerate or decelerate the preexisting trends towards improving sustainability efforts in the fast fashion industry.

Sustainability, according to the definition adopted by the United Nations World Commission on Environment and Development, is "being able to satisfy current needs without compromising the possibility for future generations to satisfy their own needs"' (World Commission on Environment and Development,1987, pg. 41). Moreover, as it pertains to business and the fashion industry, sustainability can be examined as sustainable business model innovation, which has been defined as " (...) innovation to the way business is done by creating a competitive advantage through superior customer value while contributing positively to the company, society, and environment while minimizing harm”' (Bocken et al., 2015).

The demand for fast fashion has contracted as consumers experience reduced purchasing power due to soaring unemployment from COVID-19. Discretionary purchases like apparel dwindle in times of economic recession. A redefined focus on necessity versus luxury leads to changes in consumer perceptions of value. This prioritization of value is evidenced as more 
consumers are buying secondhand items than ever before. According to data analytics and consulting firm GlobalData's Market Sizing and Growth estimates, the online secondhand apparel sector is expected to grow $69 \%$ between 2019 and 2021. During the same time period, the retail sector as a whole is predicted to contract by $15 \%$ (thredUP Inc., 2020). According to GlobalData Market Sizing, the total secondhand market is expected to outgrow the fast fashion market to almost twice its size by 2029 (thredUP Inc., 2020).

Furthermore, government lockdowns and the disruption of travel and large social gatherings have reduced the need for constantly evolving styles and new clothing and have increased the demand for at-home loungewear. The added at-home time from lockdowns has also led to surges in at-home and DIY projects. According to GlobalData Consumer Survey, 50\% of people are cleaning out their closets more than they were pre-pandemic (thredUP Inc., 2020). This has led to an increase in upcycling and selling and donating clothing to thrift and resale stores. Finally, the in-store experience of apparel shopping has either been completely eradicated due to lockdown mandates, or fundamentally changed due to the inability to try on items in-store to maintain sanitary measures.

There is a range of potential ways to look at this pertinent issue, but this report will focus on the demand side, specifically the consumer shift generated by the pandemic and whether that shift will accelerate the transition towards more sustainability in the fashion industry. This study will provide two probable impacts of COVID-19 on the sustainability of the fast fashion industry. First, there will be a time of immediate recovery post-pandemic where companies are likely to forgo sustainability funding to minimize expenses and maximize profits after this economic slump. This will mean the low dollar cost, yet high environmental cost of the fast fashion business model will likely remain present in the short term. As companies recover and 
find that consumers' behaviors are changing due to the pandemic, a second and more sustainable implication will come into effect that will have lasting repercussions on the fashion industry.

In accompaniment with the predicted future implications, this report will provide recommendations based on the insights and studies compiled in this study for how to best navigate the unprecedented future post-COVID-19 for business managers. Due to the rapidly changing developments of the ongoing COVID-19 pandemic with new variants, vaccine rollouts, and differing lockdown measures dependent on local governments, the data used in this report is as current as possible. Albeit, as a consequence of the unprecedented and unforeseen circumstances, the following predictions are subject to change.

\section{Background}

This section will provide background on the fast fashion industry, a brief summary of its extensive environmental impact, a recap of initial COVID-19 events, and the effect on the fashion industry.

\section{Fast Fashion Defined}

At a basic level, fast fashion is commonly referred to as the highly profitable business model that rapidly and inexpensively replicates the latest designer trends for mass consumption at low prices to end-users. Fast fashion relies heavily on compressed production cycles and a network of small independent manufacturers in developing countries that utilize inexpensive labor and raw materials to keep costs low (Spragg, 2012). Fast fashion has led to consumer expectations of a constant influx of new lines and styles and the perception that clothing is disposable after a few wears. Historically, fashion companies would release about four to six collections a year, centered around two seasons: spring/summer and fall/winter (Shah, 2020). 
Now, some fast fashion brands are churning out new collections weekly with 52 "micro seasons" a year (Morgan, 2015; Stanton, 2021).

The fashion industry is characterized by its high stock turnover, frequent changes in market demand, and intense competition. Therefore, in order to compete in the industry and rapidly respond to changes, the fast fashion supply chain uses numerous agents in multiple countries. The ever-increasing trends in technology, communication, and globalization have made the globalized and lengthy fast fashion supply chain possible (Pedersen et al., 2016). Fashion companies contract independent agents at most levels of their supply chain. This leads to a lack of transparency and accountability on the processes used and adherence to ethical and sustainable practices. There are many players in the fashion industry supply chain, including but not limited to designers, creative services firms, modeling and talent agencies, manufacturers, importers, exporters, wholesale distributors, retailers, textile and other raw materials suppliers, and trade associations (Practical Law, 2021).

\section{Environmental Impact of Fast Fashion}

The fashion industry as a whole, and especially fast fashion, reaps expansive and devastating environmental harm on the planet. The fashion industry is known for being systematically opaque about supply chain practices and environmental impacts. In order to eventually remedy this colossal issue, it is crucial that there is an ongoing interaction between consumers, businesses, and governments since contributions from all three entities are needed to mitigate the negative externalities of the fast fashion industry.

The numerous avenues of unsustainable practices derived from the fashion industry make it so notably harmful (Ellen MacArthur Foundation, 2017). The fashion industry is responsible for extreme pollution, releasing vast amounts of greenhouse gases into the atmosphere, extensive 
water use and pollution, and obscene amounts of landfill and waterway waste (Kent, 2021). The following is a brief summary of just a few of the ways the fashion industry affects the planet.

\section{Greenhouse gases}

According to the United Nations Environment Programme, 10\% of the world's carbon emissions are a result of fashion production (United Nations Environment Programme [UNEP], 2018). This percentage is larger than the combination of carbon emissions from international flights and maritime shipping, both of which are also known for their high carbon emissions (McFall-Johnsen, 2019). The carbon emissions are generated at every step along the value chain, upstream and downstream, from initial manufacturing to transportation to supply chain intermediaries and with transportation to the end-user. According to McKinsey \& Company, manufacturing one kilogram of fabric generates, on average, 23 kilograms of greenhouse gases (Remy et al., 2020).

\section{Textile production: negative externalities}

In order to maintain the fast and low-cost production needed for the fast-fashion model, the two most commonly used fibers in fashion production are oil-based polyester and cotton. Polyester is derived from fossil fuels, and the agricultural processes needed to create cotton use a plethora of water, harmful pesticides, and fertilizers. The wastewater from the dyes that are used to color fabrics is often dumped into water systems and pollutes the water with toxins and heavy metals that adversely affect the health of local residents and animals (Bick et al., 2018; Ellen MacArthur Foundation, 2017). In fact, the second-largest source of water pollution globally is textile dyeing. As a whole, the fashion industry is responsible for $20 \%$ of the world's wastewater (UNEP, 2018). 


\section{Textile waste}

The entire product lifestyle of fast fashion from production to the product's eventual disposal wreaks havoc on the environment. Due to the constant restocking and introduction of new styles weekly, fashion companies overproduce immensely. People are now consuming more clothing than ever before; however, the overproduction is too prolific for consumer demand, even before the pandemic. Consumers were consuming more clothing pre-pandemic, but they also discarded their fast fashion items after only a few wears.

Americans consume nearly 3.8 billion pounds of clothing annually; of that amount, about $85 \%$ is sent to landfills as solid waste, accumulating to almost 80 pounds of solid textile waste per American per year (Bick et al., 2018). In other words, on average, for every five garments produced, about three end up in a landfill or incinerated each year (Remy et al., 2020). The incinerated textile waste then results in additional greenhouse gas emissions. Microfiber waste from clothing is also rampant. Since polyester is synthetic and a plastic, it does not break down in oceans and other bodies of water (McFall-Johnsen, 2019). Annually, 500,000 tons of microfibers end up in the ocean due to consumers washing their clothes (UNEP, 2018).

Before the pandemic, only $60 \%$ of garments were sold at full price, proving the extreme over-production of the fast fashion business model (Kent, 2021). Once the pandemic hit and orders were canceled as they were unable to be filled by suppliers in Asia, excess inventory piled up during lockdowns, further proving the extreme over-production of the fast fashion industry and how it is not only environmentally but also economically damaging.

\section{Fashion Retailers Adopting Circular Business Models}

Due to the extreme negative externalities, such as environmental damage and economic losses from underutilization and over-production, many fashion retailers started to assess 
potential strategies and popular sustainability trends to reduce their harmful impact prepandemic. The appearance of terms such as "sustainability" and "sustainable" have more than doubled in the annual reports of 15 of the largest global fashion companies since 2015. Usage of "sustainability" and "sustainable" now appear as frequently as the fundamental financial terms "profit" and "growth" (Kent, 2021). This indicates that the importance of sustainability from a company perspective is growing and that it is imperative for firms to integrate financial and sustainable initiatives in recovery post-pandemic.

Similar to many sustainability trends, circular business models were gaining traction prepandemic, but the trend heightened during COVID-19. This section will briefly summarize some of the fashion retailers embracing the circular business model trend and showing interest in resale, rental, and repair programs.

The circular business model trend was gaining traction pre-COVID, as $87 \%$ of clothing retailers wanted to test trial resale models, and $61 \%$ were interested in trying rental models back in 2019 (thredUP Inc., 2019). According to a GlobalData Fashion Retailer Survey that asked retail executives about the primary motivators for testing resale, $82 \%$ said to increase foot traffic, $66 \%$ said to benefit the environment, and $58 \%$ said to appeal to a younger demographic (thredUP Inc., 2020). Rental and resale business models are experiencing growth that is projected to continue. Between 2019 and 2023, rental business model revenue is expected to increase by $\$ 801$ million with a compound annual growth rate of $11 \%$. On the other hand, the resale sector is predicted to grow by $\$ 18$ million between 2018 and 2023. These estimates were determined before the consumer preference shifts towards increased sustainability, value, and cost savings derived from COVID-19, which means that these sectors are likely to experience further growth 
moving forward. Thus, retailers must integrate these profitable and economically beneficial business models in their post-pandemic recovery plans.

Levi's recently started a new circular initiative called Levi's Taylor Shops, where consumers can send in their old Levi's items to be redesigned and repaired. Initiatives similar to this, once adopted by numerous firms, can significantly reduce the harmful environmental effects of the fashion industry. Even the slightest extension in the length of a single article of clothing's lifespan can make a sizable impact. Simply wearing a pair of jeans for ten months longer will reduce its water footprint by $23 \%$ and its carbon footprint by $18 \%$ (Levi Strauss and Co., 2020). According to the Green Story Inc. Environmental Study, the act of giving a single dress a second life through resale reduces its carbon footprint by 79\%; and buying mainly secondhand clothing is the most significant way a consumer can reduce their fashion carbon emission footprint by 527lbs annually (thredUp, 2020).

Beyond individual brands, large department stores like Selfridges in the United Kingdom are adopting circular business models and started them during the pandemic. Selfridges started a "repair concierge service," a rental program, and a resale program called "Resellfridges" in the summer of 2020 (BBC, 2020). Selfridges will partner with Hurr Collective, an online clothing rental company, to manage the rental portion of their new sustainable business plan. Under the rental program, customers can rent items for 4, 8, 10, or 20 days. Furthermore, the repair concierge service will repair both items bought at Selfridges and elsewhere (BBC, 2020).

These are just a few of numerous retailers and companies that have already moved in on transitioning and adopting circular business models. Fashion firms need to invest in circular business models to mitigate many of the negative environmental externalities of fashion 
production and disposal. There are additional steps firms can take to improve their sustainability offerings to consumers in the short term, which will be addressed in the recommendation section. COVID-19 Pandemic Timeline

The first initial cases of the novel coronavirus (SARS-CoV-2) were reported in Wuhan, China, in December of 2019. The first reported cases of the novel coronavirus in the United States were detected at the end of January 2020 (AJMC Staff, 2021). The novel coronavirus was named COVID-19 in February of 2020 (Carvalho et al., 2021). That same month, the first report of community transmission was reported in the United States. By the middle of March 2020, all 50 U.S. states, the District of Columbia, and four U.S. territories reported cases of COVID-19, although the number of cases varied by geographic location (Bialek et al., 2020). Around this same time, the WHO declared COVID-19 a pandemic, COVID-19 was named a national emergency in the United States, and a travel ban on non-U.S. Citizens traveling to the U.S. from Europe was issued.

On March 19, 2020, California became the first U.S. state to issue a statewide stay-athome order prohibiting anyone from leaving their home except for those working essential jobs or shopping for essential needs (AJMC Staff, 2021). On June 10, 2020, the U.S. reached two million COVID-19 cases. The following month, some U.S. states, including California, started to reverse their reopening plans as new one-day case numbers spiked (AJMC Staff, 2021). The stay-at-home orders worldwide and in the United States varied and continue to vary from location to location and jurisdiction to jurisdiction and are still rapidly evolving. The everchanging lockdown measures of COVID-19 account for slight differences in customer preferences and needs by geographic location. 


\section{COVID-19 Effect on the Fashion Industry}

After the travel and tourism industry, fashion and luxury are the most negatively impacted by COVID-19 of all consumer goods and services (Martinez-Pardo et al., 2020). All industries have been deeply shocked and affected due to COVID-19. However, the fashion industry was not only hit particularly hard but the instability of the fast fashion supply chain was exposed due to its lengthy delocalized nature, where most raw materials and production come from various countries in Asia, where COVID-19 first hit.

The supply chains of the fast fashion industry have been thoroughly disrupted, leaving companies scrambling to fill orders and having to cancel and refund pre-existing orders. COVID19 has left a rippling effect on every level of the supply chain due to the usage of numerous delocalized intermediaries. Bangladesh, which is the second-largest exporter of clothing in the world after China, boasting $6.4 \%$ of the global share, canceled $\$ 3.17$ billion in orders as of April 2020, only one month into widespread lockdowns in North America (Majumdar et al., 2020). According to the International Labor Organization, the global garment trade essentially collapsed in the first half of 2020 as a result of the COVID-19 pandemic (Jackson et al., 2020).

The main ways COVID-19 impacted the fashion supply chains were through factory closures and supply chain bottlenecks. Since many fast fashion supply chains utilize one country to produce raw materials and others for garment production, the countries that do not produce their own textile raw materials were hit even harder due to the bottleneck at the beginning of the system (Jackson et al., 2020). The COVID-19 ramifications on the fashion industry was different from previous economic recessions and health crises due to its bilateral nature. The impact permeated both supply and demand (McMaster et al., 2020). The following section will explain the COVID-19 impact on consumer demand. 


\section{COVID-19 Impact on Consumers}

Due to the aforementioned impacts of COVID-19, consumer behavior and values have substantially transformed throughout the pandemic. Consumer shifts brought about by COVID19 are reflected in three categories: economic changes, preference changes, and lifestyle changes.

\section{Consumer Economic Shift}

The demand for fast fashion has diminished as consumers have less purchasing power. COVID-19 has left many people laid off, furloughed, experiencing decreases in pay, or feeling forced to reduce work hours. According to U.S. Bureau of Labor Statistics data, the April 2020 national unemployment rate of $14.8 \%$ was the highest in recorded history since data collection started in 1948 (Falk et al., 2021). At the end of 2020, the national unemployment rate decreased to $6.7 \%$ in December but remained nearly twice as high as the rate pre-pandemic (Falk et al., 2021).

The economic impact of COVID-19 on individual finances has led to more mindful consumers concerned about their discretionary spending (Khusainova, 2020). According to Accenture, health, safety and finances are consumers' top priorities (Accenture, 2020).

Consumers are spending more time at home due to lockdowns and health and safety concerns. Consumers also have less purchasing power, leading to decreases in discretionary shopping. These factors have led to a major consumer shift that will leave a lasting impact on the fast fashion industry.

According to McKinsey \& Company, $40 \%$ of Americans are now more mindful about their discretionary spending due to the pandemic (Robinson \& Charm, 2020). The increase in cognizant spending has led to consumers straying away from their brand loyalty and 
demonstrating more willingness to experiment with other brands and channels (Charm et al., 2020). Value, safety, and convenience are driving consumers to experiment with new shopping behavior. McKinsey \& Company believe this trend is likely to stick, as $73 \%$ of consumers have changed stores, brands, and the way they shop since the beginning of COVID-19 (Charm et al., 2020). Consumers are also more likely to shop for locally sourced products, a foreign concept in the long-delocalized supply chains of fast fashion.

Due to the economic uncertainty brought about by COVID-19, consumers are typically more likely to shop for quality and durability. Two things that can be found in secondhand purchases, a market that encompasses thrift \& donation and resale. According to a GlobalMarket COVID Survey, four out of five people turn to or are open to shopping secondhand when disposable income contracts (thredUP Inc., 2020). Thrift and donation are the more traditional methods of consuming secondhand, involving mass donations of apparel with less curation of the products before they are sold, typically in a brick-and-mortar store such as a Goodwill. Resale includes more closely curated products for resale in online and brick-and-mortar channels. Secondhand fashion is a sector that has seen growth during COVID-19 amongst widespread declines in sales of other market sectors. Online secondhand is predicted to increase by $69 \%$ between 2019 and 2021 (thredUP Inc., 2020). On the other hand, the broader retail sector is expected to contract during 2019 and 2021 by $15 \%$. All of resale is set to grow $414 \%$ in the next five years (Ellen MacArthur Foundation, 2020).

According to a GlobalData Survey, $79 \%$ of consumers plan to reduce their apparel budget in the next year (thredUP Inc., 2020). This means that consumers are likely not to buy as many clothes in general; however, they will likely steer towards longer-lasting, durable apparel when given the opportunity to shop. An easy way consumers can reduce their spending while 
maintaining a constant influx of new clothing items is through fashion rental services. The clothing rental business model took a hit at the beginning of the pandemic due to sanitary concerns and the extended pause of social events; however, rental is expected to bounce back once lockdowns and social distancing measures ease up. This expected surge has already been witnessed in China, where YCloset, an online rental platform backed by e-commerce behemoth Alibaba, experienced an increase in renting as lockdowns in China eased in March of 2020 (Chan, 2020).

In the next five years, shoppers plan to spend 52\% more on secondhand clothing, $43 \%$ more on sustainable fashion, and $28 \%$ more on rental fashion. On the other hand, consumers plan to spend $24 \%$ less on fast fashion, and for the first year ever, fast fashion did not experience a growth in market share (thredUP Inc., 2020). Consumer plans to spend on sustainable fashion jumped $138 \%$ from the previous year, proving that consumers are shifting towards adopting more sustainable behavior.

\section{Consumer Preference Shift}

As of late, consumers have become more aware of environmental and social issues present in the fast fashion business model. According to The State of Fashion Report by McKinsey \& Company and the Business of Fashion, "the pandemic has amplified public awareness of social injustice in the supply chain" (Amed, Berg, Young, et al., 2020, pg. 45). Furthermore, according to a Boston Consulting Group (BSG) survey of over 3,000 people from 8 countries, $70 \%$ of participants said they have become more aware now than before the pandemic that human activity threatens the climate, which degrades the environment and, in turn, threatens humans (Kachaner et al., 2020). The increased environmental awareness has been reflected in the purchasing decisions of consumers. According to Accenture, $61 \%$ of consumers are making 
more environmentally friendly, sustainable, or ethical purchases and $89 \%$ of them say they are likely to continue it post-pandemic (Accenture, 2020).

The effect that this colossal public health crisis has had on consumer perceptions can be attributed to the nature of the event being health-related, media coverage of environmental shifts throughout the pandemic, and the increase of time spent on social media throughout lockdowns. Moreover, $76 \%$ of BSG survey respondents believe that environmental issues are just as or more concerning than health issues. About $70 \%$ of respondents want companies to prioritize environmental issues; $54 \%$ believe that companies' recovery plans post-pandemic should prioritize environmental and economic issues equally; $16 \%$ feel that environmental issues should take precedence over economic recovery (Kachaner et al., 2020).

Another factor impacting consumer shifts post-COVID-19 is that there are increasingly more young consumers who are more active in e-commerce shopping and on social media. Gen$\mathrm{Z}$, which is the generation of people born after 1996, made up more than $40 \%$ of global consumers in 2020 (Parker \& Igielnik, 2020). Out of all generations, Gen Z and Millennials are most likely to believe that human activity causes global warming (Parker \& Igielnik, 2020). Furthermore, Gen $\mathrm{Z}$ is the generation most rapidly adopting secondhand fashion, followed by Millennials (thredUP Inc., 2020). In 2019, $40 \%$ of Gen Zers bought secondhand, and so did 30\% of millennials (thredUP Inc., 2020).

Younger generations prioritize environmental issues and are more open to changing their consumer behavior (Kent, 2020). Many people believe that there is no room for growth in the secondhand market due to stigmas around buying used clothes. However, $80 \%$ of Gen Zers do not believe there is a stigma to buying used fashion (thredUP Inc., 2020). 


\section{Consumer Lifestyle Shifts}

History has repetitively shown that global crises accelerate societal shifts (Reeves et al., 2021). For example, during the 1918 Spanish Flu, the last global pandemic of a comparable caliber, behavioral shifts led to new business opportunities. Personal hygiene and the importance of cleanliness increased after the Spanish flu onset, which led to an increase in the frequency that people washed their clothing and the emergence of electric washing machines (Martinez-Pardo et al., 2020). WWII resource rationing led to more timeless styles and reusing materials to create new articles of clothing (Imperial War Museums, n.d.). The 2003 SARS outbreak led to longlasting shifts in retail consumption patterns, as more consumers opted to utilize online shopping in place of traditional brick-and-mortar shopping (Martinez-Pardo et al., 2020).

Fashion styles and buying channels have been drastically affected since people are staying at home due to local lockdown restrictions and their personal safety choices. There has been a massive surge in online shopping since the onset of COVID-19. According to Accenture, since the pandemic onset, there has been a $169 \%$ spike in e-commerce purchases from new or low-frequency users (Accenture, 2020). This e-commerce spike can also be attributed to the changed in-store shopping experience. Due to sanitary measures, many stores do not allow consumers to try on items before buying them, which used to be the predominant draw of brickand-mortar shopping and a limitation of online shopping. According to the Mckinsey Global Fashion Index, of the top 20 fashion companies with the highest economic performance and profits throughout the pandemic, digital strength is a key characteristic (Amed, Berg, Young, et al., 2020). Purely internet-only fashion retailers experienced a $76 \%$ stock price growth from December 2019 to October 2020. During that same December to October time period, internet 
retailers traded $42 \%$ higher on average by indexed stock valuation than all other fashion companies (Amed, Berg, Young, et al., 2020).

As the majority of consumers remain at home under stay-at-home orders, new in-home activities are popping up. According to a GlobalData COVID Survey, $88 \%$ of consumers started practicing a new thrifty hobby during the pandemic, like mending clothes, that they plan to continue after lockdowns ease up (thredUP Inc., 2020). Moreover, 50\% of consumers have said that they are cleaning their closets out more now than pre-pandemic (thredUP Inc., 2020). The increase in closet cleanouts and mending/upcycling apparel aligns with increased inventory for secondhand fashion and the consumer shift towards increased environmentally friendly behavior. Two-thirds of consumers who have never previously sold their clothes are now open to it (thredUP Inc., 2020). The top four reasons people sell their clothes are to make additional income, help the environment, earn money to buy more clothes, and to create more space in their closets. The increase in closet cleanouts has led to an abundance of inventory for resale.

The other significant impact of coronavirus lockdowns is the reduced demand for buying multiple outfits for social events. According to a Green Story Inc. Environmental Study, prepandemic, one out of every two shoppers said they did not want to be seen wearing the same outfit more than once, and 70\% said they had purchased single-use outfits (thredUP Inc., 2020). Now that people are not able or allowed to gather and socialize like before, the need for multiple outfits and new styles, a primary driver of the fast fashion business model, has dwindled. Consumer preferences for comfort and loungewear have drastically increased as people worldwide quarantine at home (Khusainova, 2020). According to the Mckinsey Global Fashion Index, of the top 20 economic performing clothing companies, sportswear companies reported a 7\% stock price increase from December 2019 to October 2020, while most clothing companies 
are experiencing stock price drops (Amed, Berg, Young, et al., 2020). Consumers are opting for athleisure, sportswear, and loungewear while working and learning at home. Furthermore, the reduced socialization has led to less of a demand for multiple one-use fast fashion items.

There is a direct correlation between the strictness of stay-at-home orders and consumer demand across the globe. Countries with the strictest lockdown policies have lower levels of annual retail sales growth compared to countries with less strict lockdown orders. The least stringent countries have over $25 \%$ higher annual retail sales growth than the strictest countries. Countries with a medium level of stringency on their lockdown protocols have $10 \%$ higher annual retail sales growth than the strictest countries (Jackson et al., 2020).

\section{Consumer Role}

In order to improve sustainability in the fashion industry, the responsibility lies on both the consumers and the producers. According to McKinsey \& Company, changes in consumer behavior alone could lessen the fashion industry's carbon emissions by $21 \%$, and another $18 \%$ could be abated by brands improving their operations (Berg et al., 2020). Therefore, the consumer preference shifts catalyzed by the repercussions of the COVID-19 pandemic can immensely reduce the negative environmental impacts of the fashion industry. The potential for an environmentally positive industry change derived by pandemic consumer shifts does not account for the massive supply chain and operational impact generated by the pandemic. The supply chain and operational impact are also monumental in that they brought the fashion industry's weaknesses out of the dark and into full transparency.

According to a study that extended the theory of planned behavior to sustainable consumption, there are six cardinal barriers to sustainable fashion consumption. The barriers include a lack of knowledge and awareness about the industry's environmental impacts, the 
perception that sustainable fashion comes at a higher price with lower product variety, and is perceived as less stylish. Furthermore, additional barriers include the perceptions that sustainable apparel is less available and accessible and the skepticism of fashion companies' sustainability claims (Brandão \& Costa, 2021). These barriers boil down to environmental apparel knowledge, perceived value, price sensitivity, product attributes, and variety, availability, and skepticism (Brandão \& Costa, 2021). In addition to the reduced purchasing power of consumers brought about by the pandemic and recession, COVID-19 has led to more consumer environmental awareness, reduced stigmas surrounding sustainable fashion, and more sustainable fashion availability as the online secondhand apparel sector has experienced growth throughout 2020 (thredUp, 2020). Consumers are experiencing shifts in their finances, lifestyle, and values due to the pandemic, which will accelerate the shift towards more sustainability in the fashion industry as companies will feel pressure to respond to these substantial shifts.

\section{Implications for Fashion Retailers}

The global crisis that is COVID-19 has put all market sectors into a tailspin. Therefore, it is now crucial for fashion firms to capitalize on pivoting their business strategies early on to be ahead of other firms during recovery. Fashion companies are experiencing an unprecedented drop in revenue due to the aforementioned supply and demand disruptions of the pandemic. Many companies are struggling to stay afloat and survive this global crisis. For the first time, fast fashion market share did not grow, and most shoppers plan to reduce their fast fashion spending in the next five years. Furthermore, the secondhand market is expected to grow to twice the size of fast fashion by 2029 (thredUP Inc., 2020; Ellen MacArthur Foundation, 2020). Consequently, it is imperative that all fashion companies, but particularly fast fashion companies, use business model innovation in their recovery post-pandemic. 
Most fashion companies will want to focus only on economic recovery; however, in order to remain relevant in the eyes of consumers after COVID-19, sustainability must be at the forefront of recovery efforts (Ricchetti \& De Palma, 2020). Many companies will fall into two stages of recovery. The first immediate stage will be short-lived but focus less on sustainability and more on economic recovery. The second stage will be longer-lasting and will emphasize a consumer and industry shift towards more environmentally conscious preferences (Challawala, 2020). Rather than this linear progression, fashion companies should intertwine sustainability in their economic recovery to utilize consumer preference shifts and take advantage of environmentally friendly business models. The increase in technology and digitalization brought about by COVID, paired with the latest consumer preferences, will lead to innovative business models that will provide additional revenue streams to recovering fashion retailers.

Brand sustainability and economic gains are not mutually exclusive. On top of the potential for increasing revenue streams by capitalizing on the customer preference shift towards sustainability, companies can garner more investor support by adopting sustainable practices. Environmental, social and governance (ESG) investing is on the rise since the onset of the pandemic. According to JP Morgan Research, investors are calling COVID-19 the first sustainability crisis of the 21 st century (J.P. Morgan Chase \& Co., 2020). The preexisting economic trends prior to the pandemic are now accelerating (Papadopoulos et al., 2020). Fashion retailers, especially fast fashion retailers, need to recognize this and position themselves ahead of the massive sustainability preference shift to maximize the value delivered to all stakeholders. There is a widespread understanding amongst business and investment professionals that ESG can significantly impact company value. Furthermore, managing and mitigating environmental, social, and governance risks can safeguard and improve the economic value of companies 
(Papadopoulos et al., 2020). Proof of this shared understanding and how COVID has led to a consumer shift in more sustainable purchasing and investing is that the total assets in sustainable funds reached their highest peak at the end of 2020 at almost $\$ 1.7$ trillion (Kent, 2020).

Many firms have formed sustainability coalitions like Zero Discharge of Hazardous Chemicals and The Better Cotton Initiative to tackle industry-wide sustainability issues (Remy et al., 2020). This is a step in the right direction, and more fast fashion retailers should join sustainable coalitions to aid in properly integrating sustainability in recovery. However, fashion firms need to tackle sustainability on their own to supplement coalitions and government efforts. Companies can accomplish this by integrating sustainable practices and eco-friendly business models in post-pandemic recovery plans.

Sustainable business model trends existed before the pandemic; however, adopting these business models has never been as crucial as it is now. The fashion industry has ten years to play its part in helping the global economy avoid irreparable climate change damage. Fast fashion is a preeminent player of the broader fashion industry that must address and correct its detrimental environmental burden. COVID-19 changed consumer preferences, and this global catastrophe is the time to pivot towards a more sustainable future. Once companies make it easier for consumers to be educated and excited about making sustainable choices, environmental and economic benefits will follow. According to McKinsey \& Company, adopting a "more conscious approach to fashion consumption, changes in consumer behavior during use and reuse, and the introduction by brands of radically new business models" could reduce 347 million metric tons of carbon emissions by 2030 (Berg et al., 2020, paras. 11). 


\section{Recommendations for Fashion Retailers}

All fashion companies, but specifically fast fashion companies, need to take stock in the consumer preference shift brought about by COVID-19 to best compete in the market throughout the rest of the pandemic and post-pandemic. While observing company behavior at home during lockdowns, consumers have shown that they care about companies' actions and aid efforts during this unprecedented global health crisis and recession, and $73 \%$ of consumers plan to support companies that aided those in need during COVID-19 (thredUp, 2020). Consumers are more likely than ever to abandon their brand loyalties. Therefore, this is simultaneously when firms can make early moves to emerge at the front of the market and when established brands can fall to the wayside. The increased transparency and awareness surrounding fashion's negative environmental impacts have damaged consumers' perceptions of fashion companies. Firms must integrate sustainability at the forefront of their recovery post-pandemic. Crucial steps for business managers to take to improve their brand sustainably include: developing traceable and enforceable universal supply chain environmental standards, marketing plans and product information that emphasize environmental awareness and transparency for customers, condensing and localizing supply chains, investing in brand resale, repair, and reuse programs, and replacing traditional fibers and packing for options that are more environmentally friendly. The steps that fast fashion companies and companies in the broader fashion industry should adopt break down into two main categories: 1) provide transparency and sustainability information and 2) integrate circular business models.

\section{Provide transparency and sustainability information}

COVID has diminished the barriers to sustainable fashion consumption. However, consumers are more likely to practice sustainable consumption if the time and energy spent 
finding sustainable alternatives and products are minimal (Mukendi \& Henninger, 2020).

Overall, consumers want to buy more sustainable products and are willing to receive more information on sustainability; however, most do not know how to get it and are not likely to take the time to research it on their own. Sustainability information can be best provided through developing sustainability point systems, tagging products, grading products, and providing additional post-purchase information.

Fashion companies need to make environmental information clear, concise, and readily available. Furthermore, the market is highly saturated with numerous sustainability certifications. The plethora of sustainability certifications can be confusing and do not resonate with consumers. Thus, companies need to present environmental information to consumers in an easily accessible and understandable way. The information needs to be simple, straightforward, and evident to the consumer online, in-store, and once they purchase an item.

Consumers will only make more environmental choices if they are educated about the negative externalities of the fashion industry. Therefore, fashion firms, specifically fast fashion firms, must provide more transparency post-pandemic about their operations and sustainability. Companies need to increase supply chain transparency to better evaluate and address environmental issues at each level of the chain and demonstrate positive environmental behavior for stakeholders (Sustainable Apparel Coalition, 2020). Stakeholders and customers will be more interested in investing in sustainable companies post-pandemic due to the shift in preferences brought about by the pandemic-induced lockdowns and recession.

COVID-19 has led to a dramatic increase in online shopping. Thus, sustainability information should be provided on e-commerce sites on the product browsing and searching pages of websites. Information should also be displayed at checkout, where brands will inform 
their customers about the environmental impact of their purchase, the shipping, and the packaging. Therefore, companies and consumers will both carry the responsibility of making more environmentally friendly choices.

\section{Sustainability Point Systems}

Once a consumer makes a more sustainable choice, such as buying an item that has been upcycled or has had a more localized production history, they can start to gather sustainability points that can represent the amount of water or carbon saved by their choice. These points and data can then be shown on consumer online shopping accounts and in email marketing. This point system could operate similar to loyalty programs that will reward customers with deals in the future. The sustainability points will encourage more sustainable choices on the consumer end and increase customer loyalty, which has diminished due to the pandemic.

\section{Tagging products to trace sustainability}

In conjunction with the increased digitalization trends, all fashion companies, but specifically fast fashion companies, should tag garments with radiofrequency identification (RFID) technology to track items throughout the supply chain. RFID chips use radiofrequency waves to transfer data almost instantaneously without physical contact. Once fashion companies tag their items with RFID chips, each stop along the supply chain can be traced and tracked. This real-time data can be used internally and externally to increase the overall sustainability of the firm.

The data derived from these tags can be used internally to monitor and encourage sustainability and environmental efforts throughout production. Internal tag data can then be utilized to reward the independently contracted manufacturers that meet and exceed sustainability goals. On the other hand, companies can subsequently cut ties with the contracted 
manufacturers that do not prioritize sustainable practices. Once universal supply chain environmental standards are established by legislation and or become industry-wide expectations, companies can be evaluated and ranked based on their tag data. Similar to accounting audits, companies can be audited for their tag data to monitor and track that they are meeting universal supply chain environmental standards.

The tag data can also be used externally in marketing initiatives so the now more environmentally aware and conscious consumer can track their garments' lifespan through the supply chain and beyond. The software company EVRYTHNG and packaging maker Avery Dennison have partnered up and already started this tagging technology (Remy et al., 2020). While searching for items on e-commerce sites, consumers will see a number stamp representing how many countries a garment has gone through before reaching the end-user. On the product page and at checkout, consumers will see a more extensive supply chain map of the item. Similar to other environmental information, supply chain maps are already available for consumers. However, this information is not easily accessible; it is not at the forefront of a consumer's mind when making a purchase. Thus, this information must be present both on the search result page and under the product's details.

\section{Grading products based upon their sustainability}

In conjunction with the sustainability point system and tagging system, fast fashion companies should start grading their products based upon their environmental impact.

Companies will use the tag data in their grading system of garments. Grades need to be displayed in an unambiguous manner, such as based upon colors or a letter grade. The product grading will correlate to the points that consumers earn based on their purchases of each products' grades. 
In the third quarter of 2020, Amazon started the Climate Pledge Friendly initiative, which engages consumers to make sustainable decisions when shopping on Amazon. The Climate Pledge Friendly label will appear next to products that meet a sustainability certification in the search results and on the products page (Amazon Staff, 2020). Amazon is taking an excellent step towards putting the consumer in control of making eco-friendly choices. Fashion companies should not only adopt a similar program on their own e-commerce sites but also need to ensure that their products will be eligible for a Climate Pledge Friendly label since Amazon fashion is poised to grow in the next year (thredUP Inc., 2020).

In the next year, the three sectors where consumers plan to spend more are secondhand, Amazon-fashion, and off-price retailers. Amazon Fashion is set to grow by $37 \%$ in the next year (thredUp, 2020). Once Amazon's Climate Pledge Friendly label and brand-specific sustainability grades become commonplace in the market, firms that are late movers will appear less sustainable to the new, more environmentally conscious customer. In order to make it even easier for a consumer to make sustainable purchase decisions, Amazon and other retailers should integrate search criteria filters based upon the sustainability grades and tag data. Therefore, consumers can view products from most to least sustainable and can also completely eliminate less sustainable options from their search results.

\section{Provide Post Purchase Sustainability Information}

In addition to marketing plans displaying sustainability efforts throughout the supply chain and educating consumers on making more sustainable purchases, fashion companies should educate their customers about making environmentally conscious decisions postpurchase. Examples include how to best care for their apparel and how to reuse and repair old clothing items. For example, if one person stops machine drying their clothing and replaces it 
with air drying, they will, on average, reduce their carbon footprint by 447lbs annually.

Furthermore, encouraging simple changes like simply washing four out of five loads in cold water can save $864 \mathrm{lbs}$ of carbon annually (Cold Water Saves, n,d.). Firms can provide this information in the shipping confirmation email and on the physical tag on garments. All fashion companies, including fast fashion companies, need to combine this educational marketing with the promotion of new fibers, materials, and designs that will extend the length of garments. More durable fibers and designs will last through more washes and can be washed and dried in more sustainable ways. Longer lasting products will benefit the environment and companies by strengthening brand loyalty.

\section{Integrate Circular Business Models}

As previously mentioned, circular business models are growing in popularity amongst consumers and retailers throughout the pandemic. Longer-lasting fashion coincides with the growing trend for fashion companies to start their own circular initiatives or join in on circular partnerships with online and app-based resale companies. Some fast fashion companies have already dipped their toes in circular business models, but this adoption needs to occur across all fast fashion retailers.

Buying mainly secondhand clothing is the number one way consumers can reduce their fashion carbon footprint (thredUP Inc., 2020). Circular business models can lessen the environmental issues that arise downstream in the value chain, an area that is frequently overlooked in improving sustainability (Hvass, 2015). In addition to the negative environmental impacts that come from the lack of recycling of apparel, clothing underutilization and the lack of recycling have negative economic impacts. Pre-COVID, more than $\$ 500$ billion of value was lost every year as a result of a lack of recycling and clothing underutilization (Ellen MacArthur 
Foundation, 2020). This proves that increasing sustainability can coincide with increasing the bottom line for fashion companies. Circular initiatives and partnerships can increase revenue streams, strengthen customer loyalty and broaden brand awareness (Hvass, 2015; thredUp, 2020).

Once consumers recycle an old item, they can earn more sustainability points that will lead to discounts on buying additional repurposed or recycled items. This circularity creates an experience for the customer that goes beyond the product (Magyar, 2021). Patagonia, a market leader for sustainable practices in the fashion industry, offers repair services for Patagonia garments and collects used clothing from customers in their stores and through the mail to lengthen the lifespan of their products (Remy et al., 2020).

Patagonia and H\&M have partnered with I:COLLECT, also known as I:CO, to collect clothing and footwear for recycling and reuse (Remy et al., 2020). I:CO offers services that make it easier for companies to recycle and reuse their products. I:CO designs custom collection bins and places them in the partnering retailers' stores so customers can return their items. After the point of sale, I:CO sorts each item specifically to the needs of each retail partner. Then, items are identified and prepared for recycling. Some products are purely reused; some of the unwearable items stay in a closed loop and can then be broken down and reintegrated into retailer supply chains. Other items end up in open loop recycling for other industries (I:CO, 2018). The energy needed to collect, sort and resell secondhand apparel is 10 to 20 times less than the energy required to make a new product (Hvass, 2015). I:CO is just one example of a service that firms can utilize to make the integration of circular business models easier.

This is not an exhaustive list of recommendations for fashion retailers and manufacturers, rather a few recommendations that will capitalize on the consumer shift generated by COVID- 
19. The recommendations that fall under part one, providing more sustainability information to consumers, can be adopted on a shorter timeline due to increased digitalization with fewer risks and costs. Commencing circular business model partnerships and initiatives will require a longer timeline and funding. However, it is a necessary investment for not only the ethical side of protecting the environment but also to appeal to the new and improved consumer post-pandemic. A summarized list of recommendations for fast fashion retailers is as follows:

1. Make sustainability information about each product transparent, easily accessible, and understandable in a clear and concise way. Possible methods of attaining this include:

a. Ranking/grading system of products bases upon colors or letter grades

b. Include product search preferences and filter criteria based on the aforementioned sustainability grades

2. Tag products to track them throughout the supply chain, and use this information to:

a. Monitor the sustainability practices and maintain environmental standards of supply chain intermediaries

b. Provide information to customers through supply chain maps and product sustainability rankings

3. Educate consumers on how to make sustainable decisions post-purchase

4. Integrate circular business models with resale, repair, and rental services by partnering with resale companies or creating in-house departments dedicated to circular initiatives

\section{Conclusion}

The fast fashion industry is an incredibly lucrative subset of the fashion industry.

Unfortunately, what makes the industry so lucrative is what makes it so exceedingly damaging to the earth. Almost exactly a year before the onset of the COVID-19 pandemic, the UN General 
Assembly announced that the world has until 2030 to prevent irreversible damage from climate change (United Nations, 2019). Then as the world came to an unprecedented halt due to the COVID-19 pandemic, the earth seemed to heal as humans slowed down. Fashion now also needs to slow down. As COVID-19 continues to ebb and flow and hopefully transitions into the recovery stages with increased vaccine rollouts, consumers and companies alike need to do their part to abate environmental damage.

COVID-19 upended the fashion industry as the extremely lengthy and unsustainable supply chains were fractured, and demand was shot. Companies will only provide more sustainable options and practice more sustainability if consumers demand it. Data shows that consumers have systematically changed throughout their time in stay-at-home orders and while experiencing this unprecedented pandemic. The finances, preferences, and lifestyles of consumers have dramatically shifted, impacting demand for fast fashion. Consumers are more aware of the environment and sustainability and will continue to demand this from fast fashion companies moving forward. The companies that do not acknowledge this monumental societal shift will fall to the wayside as laggards. The companies that start to integrate sustainability into their production and values will recover better from this pandemic and will continue to grow their market share, brand reputation, and revenues as sustainability will only increase in importance as time goes on.

The entire fashion industry needs to shift towards increased sustainability to mimic and appeal to the consumer shift resulting from the pandemic. However, the most damaging subsect of the industry, fast fashion, must drastically reassess their traditional business model of overproduction and provide some transparency about their opaque supply chain practices. Fast fashion companies, and ultimately all fashion companies, need to provide transparency and 
sustainability information to consumers and integrate circular business models. Eventually, circular business models can be the predominant source of materials, and the need for raw materials such as farming cotton and producing polyester from fossil fuels can be phased out. The shift towards increased sustainability in post-pandemic recovery is mutually inclusive with increased economic gains as brand loyalty, and revenue streams will increase while lost value from clothing underutilization and overproduction will decrease. Fast fashion relies on mass production of the latest fads, which are new and short-lived styles, but true fashion endures throughout time. Consumers and companies must understand that sustainability is fashion and not a fad. 


\section{References}

Accenture. (2020). (issue brief). COVID-19: New habits are here to stay for retail consumers. Accenture. Retrieved from https://www.accenture.com/us-en/insights/retail/coronavirus-consumer-habits

Accenture. (2020). (rep.). COVID-19: Consumers change how they shop, work and live.

Accenture. Retrieved from

https://www.accenture.com/us-en/insights/retail/coronavirus-consumer-behavior-research

AJMC Staff. (2021). A Timeline of COVID-19 Developments in 2020. AJMC.

https://www.ajmc.com/view/a-timeline-of-covid19-developments-in-2020.

Amazon Staff. (2020, September 25). Amazon launches "Climate Pledge Friendly" program. US About Amazon.

https://www.aboutamazon.com/news/sustainability/amazon-launches-climate-pledge-frie ndly-program.

Amed, I., \& Berg, A. Balchandani, A., Hedrich, S., Rölkens, F., Young, R., Jensen, J., Peng, A. (2020). (rep.). The State of Fashion 2021. The Business of Fashion and McKinsey \& Company. Retrieved from https:/www.businessoffashion.com/reports/news-analysis/download-the-report-the-stateof-fashion-2021

Amed, I., Balchandani, A., Berg, A., Hedrich, S., Jensen, J. E., \& Rölkens, F. (2020, December 1). The State of Fashion 2021: In search of promise in perilous times. McKinsey \& Company. https://www.mckinsey.com/industries/retail/our-insights/state-of-fashion. 
BBC. (2020, August 18). Selfridges to offer clothing rental in environmental push. BBC News. https://www.bbc.com/news/business-53805033.

Berg, A., Granskog, A., Lee, L., \& Magnus, K.-H. (2020, December 14). Fashion on climate. McKinsey \& Company. https://www.mckinsey.com/industries/retail/our-insights/fashion-on-climate\#: :text=Fash ion $\% 20$ makes $\% 20 \mathrm{a} \% 20$ sizeable $\% 20$ contribution,percent $\% 20$ of $\% 20$ the $\% 20$ global $\% 20$ tot al.

Bialek, S., Bowen, V., Chow, N., Curns, A., Gierke, R., Hall, A., Hughes, M., Pilishvili, T., Ritchey, M., Roguski, K., Silk, B., Skoff, T., Sundararaman, P., Ussery, E., Vasser, M., Whitham, H., Wen, J. (2020). Geographic Differences in COVID-19 Cases, Deaths, and Incidence - United States, February 12-April 7, 2020. MMWR. Morbidity and Mortality Weekly Report, 69(15), 465-471. https://doi.org/10.15585/mmwr.mm6915e4

Bick, R., Halsey, E., \& Ekenga, C. C. (2018). The global environmental injustice of fast fashion. Environmental Health, 17(1). https://doi.org/10.1186/s12940-018-0433-7

Bocken, N. M. P., Rana, P., \& Short, S. W. (2015). Value mapping for sustainable business thinking. Journal of Industrial and Production Engineering, 32(1), 67-81. https://doi.org/10.1080/21681015.2014.1000399

Brandão, A., \& Costa, A. G. (2021). Extending the theory of planned behaviour to understand the effects of barriers towards sustainable fashion consumption. European Business Review, ahead-of-print(ahead-of-print). https://doi.org/10.1108/ebr-11-2020-0306 
Carvalho, T., Krammer, F., \& Iwasaki, A. (2021). The first 12 months of COVID-19: a timeline of immunological insights. Nature Reviews Immunology, 21(4), 245-256. https://doi.org/10.1038/s41577-021-00522-1

Challawala, A. (2020). Sustainable Fashion: Barclays Investment Bank. Barclays Investment Bank. https://www.investmentbank.barclays.com/our-insights/sustainable-fashion-will-covid-19 -accelerate-a-greener-future.html.

Chan, E. (2020, May 17). Will The Fashion Rental Market Ever Recover From Covid-19? British Vogue. https://www.vogue.co.uk/fashion/article/will-the-fashion-rental-market-recover.

Charm, T., Grimmelt, A., Robinson, K., Lu, N., Mayank, Ortega, M., ... Yamakawa, N. (2020, November 19). Consumer sentiment and behavior continue to reflect the uncertainty of the COVID-19 crisis. McKinsey \& Company. https://www.mckinsey.com/business-functions/marketing-and-sales/our-insights/a-globalview-of-how-consumer-behavior-is-changing-amid-covid-19.

Cold Water Saves. (n.d.). Cold Water Saves. https://coldwatersaves.org/.

Ellen MacArthur Foundation. (2017). (rep.). A new textiles economy: Redesigning fashion's future. Ellen MacArthur Foundation. Retrieved from http://www.ellenmacarthurfoundation.org/publications

Ellen MacArthur Foundation. (2020). (rep.). The circular economy: a transformative Covid-19 recovery strategy: How policymakers can pave the way to a low carbon, prosperous 
future. Ellen MacArthur Foundation. Retrieved from http://www.ellenmacarthurfoundation.org/publications

Falk, G., Carter, J. A., Nicchitta, I. A., Nyhof, E. C., \& Romero, P. D. (2021). (rep.). Unemployment Rates During the COVID-19 Pandemic: In Brief. Congressional Research Service. Retrieved from https://fas.org/sgp/crs/misc/R46554.pdf

Hvass, K. (2015). Business Model Innovation through Second Hand Retailing: A Fashion Industry Case. The Journal of Corporate Citizenship, (57), 11-32. Retrieved May 17, 2021, from http://www.jstor.org/stable/jcorpciti.57.11

I:CO. (2018, September 14). Homepage - I:CO. I:CO. https://www.ico-spirit.com/en/.

Imperial War Museums. (n.d.). How Clothes Rationing Affected Fashion In The Second World War. Imperial War Museums. https://www.iwm.org.uk/history/how-clothes-rationing-affected-fashion-in-the-second-w orld-war.

J.P. Morgan Chase \& Co. (2020, July 1). Why COVID-19 Could be a Major Turning Point for ESG Investing. https://www.jpmorgan.com/insights/research/covid-19-esg-investing.

Jackson, J. L., Judd, J., \& Viegelahn, C. (2020). (issue brief). The supply chain ripple effect: How COVID-19 is affecting garment workers and factories in Asia and the Pacific. International Labour Organization. Retrieved from https://www.ilo.org/wcmsp5/groups/public/---asia/---ro-bangkok/documents/briefingnote/ wcms_758626.pdf 
Kachaner, N., Nielsen, J., Portafaix, A., \& Rodzko, F. (2021, April 28). The Pandemic Is Heightening Environmental Awareness. https://www.bcg.com/en-us/publications/2020/pandemic-is-heightening-environmental-a wareness.

Kent, S. (2021). (rep.). The Sustainability Gap. The Business of Fashion. Retrieved from https://www.businessoffashion.com/reports/sustainability/measuring-fashions-sustainabili ty-gap-download-the-report-now

Khusainova, G. (2020, June 10). The Pandemic Has Changed Consumer Preferences - It's All About Health And Comfort Now. Forbes. https://www.forbes.com/sites/gulnazkhusainova/2020/06/10/the-pandemic-has-changed-c onsumer-preferencesits-all-about-health-and-comfort-now/?sh=7a2307c67cf3.

Levi Strauss and Co. (2020, January). Repair. Reimagine. Recycle. Levi's Off The Cuff. https://www.levi.com/US/en_US/blog/article/repair-reimagine-recycle/.

Magyar, J. (2021, January 19). How COVID-19 Is Nudging The Fashion Industry To Go Circular. Forbes. https://www.forbes.com/sites/sap/2021/01/12/how-covid-19-is-nudging-the-fashion-indus try-to-go-circular/?sh=6294431d2a63.

Majumdar, A., Shaw, M., \& Sinha, S. K. (2020). COVID-19 debunks the myth of socially sustainable supply chain: A case of the clothing industry in South Asian countries. Sustainable Production and Consumption, 24, 150-155.

https://doi.org/10.1016/j.spc.2020.07.001 
Martinez-Pardo, C., Razvi, A., Kibbey, J., \& Seara, J. (2020). (rep.). Weaving a Better Future: Rebuilding a More Sustainable Fashion Industry After COVID-19. Sustainable Apparel Coalition, Boston Consulting Group, Higg Co . Retrieved from https://apparelcoalition.org/wp-content/uploads/2020/04/Weaving-a-Better-Future-Covid19-BCG-SAC-Higg-Co-Report.pdf

McFall-Johnsen, M. (2019, October 21). The fashion industry emits more carbon than international flights and maritime shipping combined. Here are the biggest ways it impacts the planet. Business Insider.

https://www.businessinsider.com/fast-fashion-environmental-impact-pollution-emissionswaste-water-2019-10.

McMaster M, Nettleton C, Tom C, Xu B, Cao C, Qiao P. (2020). Risk Management: Rethinking Fashion Supply Chain Management for Multinational Corporations in Light of the COVID-19 Outbreak. Journal of Risk and Financial Management. 13(8):173. https://doi.org/10.3390/jrfm13080173

Morgan, A. (Director). (2015, May 29). The True Cost [Film]. Untold Creative \& Life is My Movie Entertainment.

Mukendi, A., \& Henninger, C. E. (2020). Exploring the spectrum of fashion rental. Journal of Fashion Marketing and Management: An International Journal, 24(3), 455-469. https://doi.org/10.1108/jfmm-08-2019-0178 
Papadopoulos, K., Araujo, R., \& Toms, S. (2020, December 27). ESG Drivers and the COVID-19 Catalyst. The Harvard Law School Forum on Corporate Governance. https://corpgov.law.harvard.edu/2020/12/27/esg-drivers-and-the-covid-19-catalyst/.

Parker, K., \& Igielnik, R. (2021, February 9). What We Know About Gen Z So Far. Pew Research Center's Social \& Demographic Trends Project. https://www.pewresearch.org/social-trends/2020/05/14/on-the-cusp-of-adulthood-and-fac ing-an-uncertain-future-what-we-know-about-gen-z-so-far-2/.

Pedersen, E. R., Gwozdz, W., \& Hvass, K. K. (2016). Exploring the Relationship Between Business Model Innovation, Corporate Sustainability, and Organisational Values within the Fashion Industry. Journal of Business Ethics, 149(2), 267-284. https://doi.org/10.1007/s10551-016-3044-7

Practical Law. (2021).Fashion Law: Overview Practice Note. In Practical Law. https://us.practicallaw.thomsonreuters.com/2-616-4923

Reeves, M., Carlsson-Szlezak, P., Whitaker, K., \& Abraham, M. (2021, April 3). Sensing and Shaping the Post-COVID Era. Boston Consulting Group. https://www.bcg.com/en-us/publications/2020/8-ways-companies-can-shape-reality-postcovid-19.

Remy, N., Speelman, E., \& Swartz, S. (2020, August 19). Style that's sustainable: A new fast-fashion formula. McKinsey \& Company. https://www.mckinsey.com/business-functions/sustainability/our-insights/style-thats-susta inable-a-new-fast-fashion-formula\#. 
Ricchetti, M., \& De Palma, R. (2020, October 9). Will COVID-19 accelerate the transition to a sustainable fashion industry? UNIDO.

https://www.unido.org/stories/will-covid-19-accelerate-transition-sustainable-fashion-ind ustry.

Robinson, K., \& Charm, T. (2020, October 15). The evolving consumer: How COVID-19 is changing the way we shop. McKinsey \& Company. https://www.mckinsey.com/about-us/covid-response-center/leadership-mindsets/webinars /evolving-consumer-how-covid-19-has-changed-us-shopping-habits.

Sabanoglu, T. (2020, November 27). Fast fashion market value forecast worldwide 2009-2029. Statista. https://www.statista.com/statistics/1008241/fast-fashion-market-value-forecast-worldwid e/\#: :text=In\%202019\%2C\%20the\%20global\%20market,was\%2036\%20billion\%20U.S. $\% 20$ dollars.

Shah, S. (2020, August 13). Can fashion shed its seasons? Five industry experts weigh in. Vogue India. https://www.vogue.in/magazine-story/can-fashion-shed-its-seasons-five-industry-expertsweigh-in/.

Spragg, J. (2012). (publication). Re-examining Agile Supply Chain Practices in Post Recession Fashion Retail. The Charted Institute of Logistics and Transport (UK). Retrieved from http://e-space.mmu.ac.uk/204229/ 
Stanton, A. (2021, March 10). What Is Fast Fashion, Anyway? The Good Trade.

https://www.thegoodtrade.com/features/what-is-fast-fashion\#: :text=Nowadays $\% 2 \mathrm{C} \% 20$ fast $\% 20$ fashion $\% 20$ brands $\% 20$ produce,back $\% 20$ in $\% 20$ the $\% 20$ early $\% 20$ aughts.

Sustainable Apparel Coalition. (2020, April 30). New Report Shows COVID-19 Puts Sustainable Fashion At Crossroads. Cision PR Newswire.

https://www.prnewswire.com/news-releases/new-report-shows-covid-19-puts-sustainable -fashion-at-crossroads-301049937.html.

thredUP Inc.. (2020, June 23). 2020 Fashion Resale Market and Trend Report. thredUP. https://www.thredup.com/resale/.

thredUP Inc.. (2019, March). 2019 Fashion Resale Market and Trend Report. thredUP. https://www.thredup.com/resale/2019?tswc_redir=true.

United Nations Alliance for Sustainable Fashion. (2020, October 23). Home-UN Alliance for Sustainable Fashion. The UN Alliance for Sustainable Fashion. https://unfashionalliance.org/.

United Nations Environment Programme. (2018, November 11). Putting the brakes on fast fashion. UN Environment. https://www.unep.org/news-and-stories/story/putting-brakes-fast-fashion.

United Nations. (2019, March 28). Only 11 Years Left to Prevent Irreversible Damage from Climate Change, Speakers Warn during General Assembly High-Level Meeting. United Nations Meetings Coverage and Press Releases. https://www.un.org/press/en/2019/ga12131.doc.htm. 
World Commission on Environment and Development. (1987). Our common future. Oxford:

Oxford University Press. 